\title{
Evaluation of Color Stability of Experimental Dental Composite Resins Prepared from Bis-EFMA, A Novel Monomer System
}

\author{
Ömer Hatipoğlu ${ }^{1^{*}}$, Emine Akyüz Turumtay², Ayşegül Göze Saygın ${ }^{3}$, and \\ Fatma Pertek Hatipoğlu ${ }^{4}$ \\ ${ }^{1}$ Department of Restorative Dentistry, Niğde Ömer Halisdemir University, \\ Niğde, Turkey \\ ${ }^{2}$ Department of Chemistry, Recep Tayyip Erdogan University, Rize, Turkey \\ ${ }^{3}$ Department of Prosthodontics, Cumhuriyet University Faculty of Dentistry, Sivas, \\ Turkey \\ ${ }^{4}$ Special Dentistry, Niğde,, Turkey \\ *ohatipoglu@ohu.edu.tr
}

Color stabilities of experimental composite resins based on Bis-EFMA (a novel bisphenol A [BPA]-free monomer system) with 3M ESPE FiltekTM Z250 (FZ) and experimental composite resins based on bisphenol A-glycidyl methacrylate (Bis-GMA) and urethane dimethacrylate (UDMA) were compared. Bis-EFMA was synthesized via the reaction between 9,9-bis[4-(2-hydroxyethoxy)phenyl]fluorene and 2-(methacryloyloxy)ethyl isocyanate. Experimental Bis-EFMA-, Bis-GMA-, and UMDA-based composites were prepared $(20 \%$ of each of Bis-EFMA, Bis-GMA, UDMA, or triethylene glycol dimethacrylate (TEGDMA) and $60 \%$ glass filler). Eighty composite resin materials were produced $(\mathrm{n}=5)$. The initial color values of composites on the first day, first week, and after the first month after immersion into black tea, coffee, cola, and water solutions were measured using a spectrophotometer (VITA Easyshade ${ }^{\circledR}$ V; Zahnfabrik, Bad Säckingen, Germany) against a white background. UDMA- and Bis-EFMA-based composite resins exhibited significantly less $\Delta E$ and $\Delta L$ compared to Bis-GMA based composite resins ( $p<$ $0.05)$. No significant difference was found between FZ and other composites $(p>0.05)$. Tea and coffee caused significant changes in total color, light value, red-green, and blue-green coordinate values changes ( $\Delta E, \Delta L, \Delta a$, and $\Delta b$, respectively) compared to water and cola ( $p$ $<0.05)$. At one month compared to one week and one day, $\Delta E, \Delta L, \Delta a$, and $\Delta b$ were significantly different $(p<0.05)$. Bis-EFMA has the potential to be used in commercial dental composites as a substitute for Bis-GMA in terms of better color stability.

Keywords: Bisphenol A, Color Stability, Dental composite material, Resin matrix

\section{Introduction}

Bisphenol A glycidyl methacrylate (Bis-GMA) was introduced to the market as the first monomer used in resin-based composites (RBCs) in the early 1960s [1]. Bis-GMA is a product of the reaction between bisphenol A (BPA) and glycidyl methacrylate and is the most widely used monomer as an organic matrix in RBCs [2]. Bis-GMA has a high viscosity due to the strong hydrogen bonds between hydroxyl groups of monomer molecules. Bis-GMA also shows less polymerization shrinkage than other monomers due to its larger molecular weight. Today, Bis-GMA continues to be the most widely used monomer in RBCs; it constitutes approximately $20 \%$ of the standard resin composite content alone or in combination with urethane dimethacrylate (UDMA). Since Bis-GMA is highly viscous, it is diluted with different monomers with lower viscosity, such as ethylene glycol dimethacrylate (EGDMA), bisphenol A dimethacrylate (Bis-DMA), or triethylene glycol dimethacrylate (TEGDMA) to facilitate clinical 
application and control viscosity [3]. Generally, among these monomers, TEGDMA is more preferred than other monomers for mixing due to its lower molecular weight. Dilutions of Bis-GMA and UDMA with TEGDMA reduce the viscosity of the $\mathrm{RBC}$, facilitates its application, and increases the degree of polymerization conversion [4].

Monomers such as Bis-GMA and ethoxy bisphenol A dimethacrylate (Bis-EMA), are generally used in dental filling materials. Bis-DMA especially is used in fissure sealants as it is degraded via hydrolysis by salivary esterases and releases the BPA component into the gastrointestinal track. BPA is considered a potential health hazard because it affects and stimulates estrogenic receptors in tissue cultures [5]. R. Pulgar, M. F. Olea-Serrano, et al. [6] reported that a significant amount of BPA (1.8 $\mu \mathrm{g} / \mathrm{mg}$ ) is released from the Bis-GMA-based composite resins. At this level BPA causes toxic effects [7]. Low doses of BPA may trigger obesity, metabolic diseases, and insulin resistance by stimulating interleukin 6 (IL-6) and tumor necrosis factor $\alpha(\mathrm{TNF} \alpha)$ secretion and inhibiting adiponectin secretion [8]. Exposure to BPA is nowadays considered a risk factor for the development and progression of obesity and other metabolic diseases [9].

Due to these negative BPA-induced effects, research is being conducted on new RBCs that do not contain Bis-GMA. To prepare these new RBCs, new methacrylate monomers, such as urethane $[10,11]$, cycloaliphatic [12,13], multi-branched $[14,15]$, silicon-containing [16], and fluorinated methacrylates [17-19] have been considered as an alternative to Bis-GMA. Although some of these monomers exhibit great advantages compared to Bis-GMA, most of them exhibit lower mechanical properties compared to Bis-GMA. In addition to the novel methacrylate monomers, many new dental applications, such as oxiranes [20-22], thiol-enes [23-25], styrenic-methacrylate [26], thiol-Michael [27], and vinylcyclopropanes [28,29] have been proposed. However, although many novel methacrylate monomers or resin systems have been developed, an alternative system to Bis-GMA with sufficient mechanical properties has not yet been found. J. He and H. M. Kopperud [30] produced a novel monomer system called Bis-EFMA derived from 9,9-bis[4-(2-hydroxy-ethoxy)phenyl]fluorene (Bis-HEPF). In their study, they compared the mechanical and biological properties of Bis-EFMAand Bis-GMA-based composites. Bis-EFMA-based composite resins showed low shrinkage, low water absorption, low cytotoxicity, and high flexural strength compared to Bis-GMA based ones. J. He and H. M. Kopperud [30] claimed that the BisEFMA monomer system is a powerful alternative to the Bis-GMA.

The purpose of this study was to compare the color stabilities of RBCs prepared with Bis-EFMA monomer system with a commercial and experimental composite resin based on Bis-GMA and UDMA monomers. The null hypotheses of this study consisted of three parts:

(1) The color stability of the experimental RBCs prepared with the Bis-EFMA monomer system is insufficient compared to the experimental based on Bis-GMA and UDMA and commercial RBCs.

(2) There is no significant difference among solutions concerning color stability.

(3) There is no significant difference among the exposure time periods in terms of color stability.

\section{Experimental}

\subsection{Materials}

Dibutyltin dilaurate (DBTL), camphorquinone (CQ), and Bis-HEPF were purchased from the Tokyo Chemical Industry (Tokyo, Japan). BisGMA, UDMA, TEGDMA, dimethyl aminoethyl methacrylate (DMAEMA), and 2(methacryloyloxy)ethyl isocyanate (MEI) were purchased from the Sigma-Aldrich Co. (St. Louis, MO, USA). Silanized glass fillers (EEG102-07-S, $\left.\mathrm{d}_{50}=0.7 \mu \mathrm{m}\right)$ were purchased from ESSCHEM Europe (Seaham, U.K.). 3M ESPE FiltekTM Z250 (FZ) as control material was purchased from $3 \mathrm{M} \mathrm{Co.}$ (St. Paul, MN, USA).

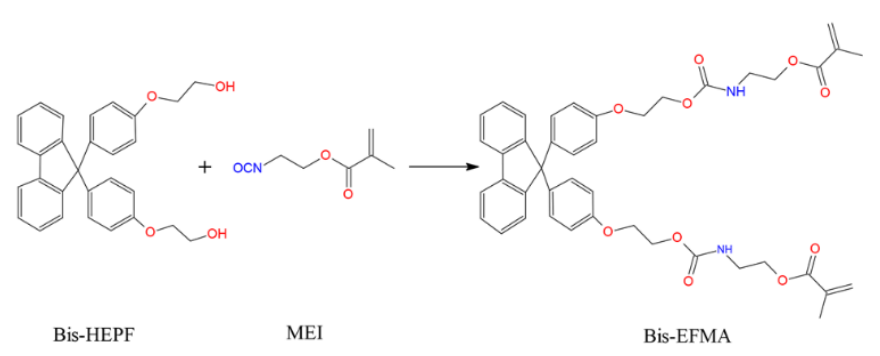

Fig. 1. Synthesis mechanism of Bis-EFMA. 


\subsection{Synthesis of Bis-EFMA}

Bis-EFMA, derived from Bis-HEPF, was synthesized via the reaction between the $-\mathrm{OH}$ group in Bis-HEPF and - NCO group in MEI as shown in Fig. 1. For this synthesis, $1.37 \mathrm{~g}$ Bis-HEPF, $1 \mathrm{~g}$ MEI, and $25 \mathrm{~mL}$ of $\mathrm{CH}_{2} \mathrm{Cl}_{2}$ containing two drops of DBTL were mixed at room temperature. The reaction process was followed by FT-IR analysis of the sample taken from the reaction medium. The disappearance of the infrared absorbance peak of -NCO group at MEI observed at $2270 \mathrm{~cm}^{-1}$ indicated that the reaction finished (Fig. 2). After the reaction was complete, most of the $\mathrm{CH}_{2} \mathrm{Cl}_{2}$ was evaporated at $25^{\circ} \mathrm{C}$ with a rotary evaporator. Large amounts of diethyl ether was poured into the remaining crude product to precipitate it. The resulting Bis-EFMA was dried in a rotary evaporator at $30^{\circ} \mathrm{C}$. Verification of the purity and structure of Bis-EFMA was examined using FT-IR and ${ }^{1} \mathrm{H}-\mathrm{NMR}$ spectra. The structure of the resulting Bis-EFMA was investigated by FT-IR. IR (BisEFMA): $v\left(\mathrm{~cm}^{-1}\right) 3361,2956,1710,1636,1607$, 1582，1506，1448，1234，1155, 1053. ${ }^{1} \mathrm{H}-\mathrm{NMR}$ $\left(\mathrm{CDCl}_{3}, 400 \mathrm{~Hz}\right)$ : 7.75-7.73, 7.36-7.31, 7.26-7.23, 7.11-7.09, 6.76-6.73 (16H, Ar-O ), $6.09(2 \mathrm{H}$, trans, $\left.2 \mathrm{CH}_{2}=\mathrm{C}\left(\mathrm{CH}_{3}\right) \mathrm{CO}\right), \quad 5.56 \quad(2 \mathrm{H}, \quad \mathrm{cis}$, $\left.2 \mathrm{CH}_{2}=\mathrm{C}\left(\mathrm{CH}_{3}\right) \mathrm{CO}\right), 5.08(2 \mathrm{H}, 2-\mathrm{NH}), 4.39-4.36$, 4.22-4.19, 4.09-4.06 (12H, $2-$ $\left.\mathrm{OCH}_{2} \mathrm{CH}_{2} \mathrm{OC}(\mathrm{O}) \mathrm{NHCH}_{2} \mathrm{CH}_{2}\right), \quad 3.48 \quad(4 \mathrm{H}, \quad 2-$ $\left.\mathrm{OCH}_{2} \mathrm{CH}_{2} \mathrm{OC}(\mathrm{O}) \mathrm{NHCH}_{2} \mathrm{CH}_{2}\right)$, $\quad 1.92$ $\left(6 \mathrm{H}, 2 \mathrm{CH}_{2}=\mathrm{C}\left(\mathrm{CH}_{3}\right) \mathrm{CO}\right)$. FT-IR and ${ }^{1} \mathrm{H}-\mathrm{NMR}$ spectra are included in Figs. 2 and 3.

2.3. Preparation of dental resin matrix and experimental composites

The experimental resin matrix was prepared by

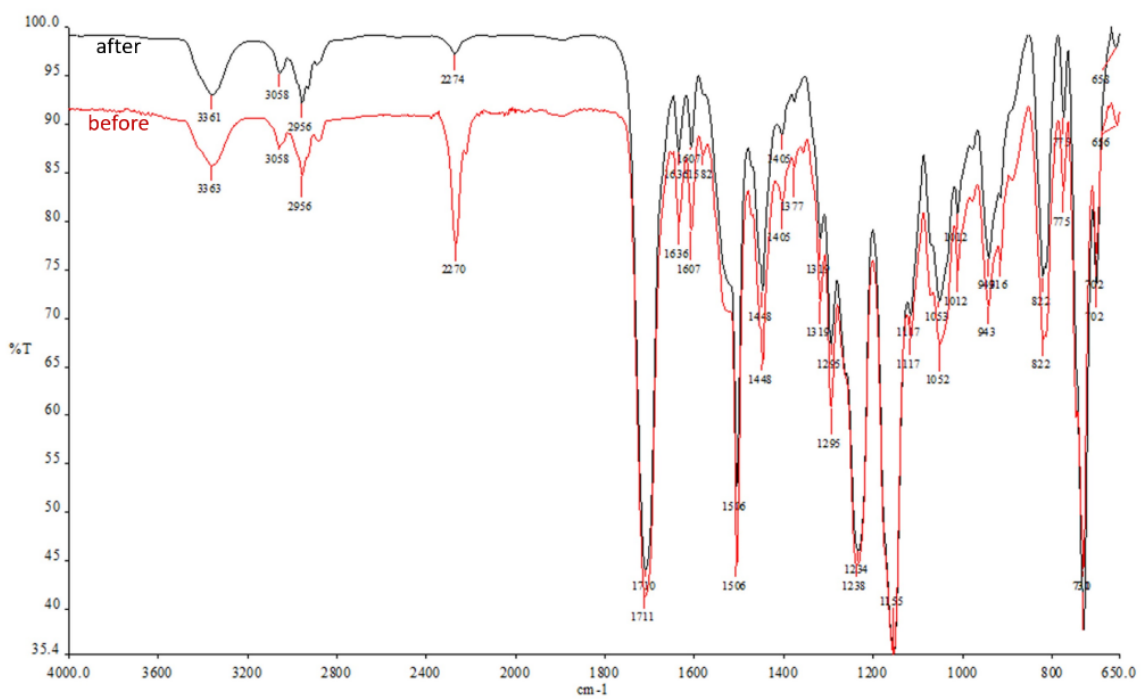

Fig. 2. FT-IR spectra of Bis-EFMA taken from the reaction medium before (red-line) and after (black-line) finalizing of the reaction.

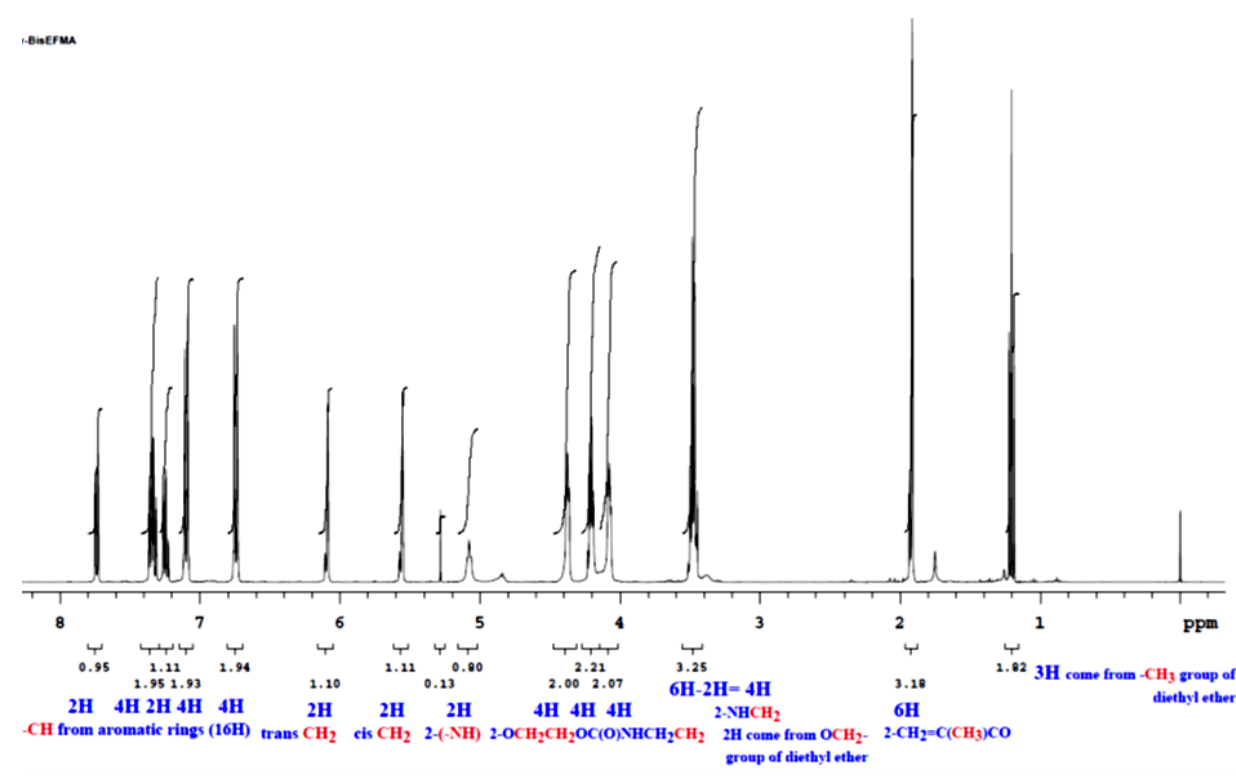

Fig. 3. ${ }^{1} \mathrm{H}-\mathrm{NMR}$ spectrum of synthesized Bis-EFMA. 
adding $50 \%$ by weight of Bis-EFMA (Bis-GMA and UDMA for control) and $50 \%$ by weight of TEGDMA and $0.7 \%$ by weight of CQ and $0.7 \%$ by weight of DMAEMA. The experimental composite resin was prepared by adding dental glass fillers to the resin matrices. The ratio of dental glass filler relative to the experimental composite was adjusted to $60 \%$ in a volume equivalent to the filler content of the FZ. The experimental resin was weighed in a mixing vessel, and fillers were added to the vessel in small portions. The composite was mixed using the Speedmixer device at $1400 \mathrm{rpm}$ for $30 \mathrm{sec}$ after the fillers were added. The properties of the experimental and commercial composite resins are shown in Table 1.

\subsection{Preparation of solutions}

Four different solutions (black tea, coffee, cola, and distilled water) were used for the study. Tea and coffee solutions were prepared according to the manufacturer's instructions. The black tea was prepared by immersing a black tea bag (Lipton yellow label tea bag tea, Turkey) in $150 \mathrm{~mL}$ of boiled water for $5 \mathrm{~min}$. The coffee was prepared by mixing $15 \mathrm{~g}$ of coffee powder (Nescafé Classic; Nestlé, Vevey, Switzerland; pH 5.56) in $200 \mathrm{~mL}$ of hot water. No special preparation methods were applied to Coke (Coca Cola Co, Atlanta, GA; pH 2.52) and distilled water solutions. The temperature of all solutions was measured using a thermometer to correspond to the standard room temperature. The solutions were refreshed regularly every day.

\subsection{Sample preparation}

Each composite material was placed in metal molds to obtain cylindrical composite samples with a diameter of $8 \mathrm{~mm}$ and $2 \mathrm{~mm}$ thickness. The metal mold was pressed with a finger pressure between two microscopic glasses covered with mylar strips to remove excess material and eliminate voids from the composite material. The BisGMA/TEGDMA, UDMA/TEGDMA, and Bis-EFMA/TEGDMA experimental composite resins and FZ composite resin were placed into the molds in one step. After the excessive materials were removed, a total of 80 composite resin materials ( $\mathrm{n}=5$ ) were polymerized for $20 \mathrm{sec}$ with a light emitting diode (LED) light source (VALO Cordless, Ultradent, South Jordan, UT, USA; wavelength $390-490 \mathrm{~nm}$; intensity 1000 $\mathrm{mW} / \mathrm{cm}^{2}$ ) according to the manufacturer's recommendations while the polymerizing LED light source was kept in contact with the glass.

\subsection{Measuring color stability}

The initial color values of RBCs and color values after one day, one week, and one month after immersion in the solution were measured using a spectrophotometer (VITA Easyshade ${ }^{\circledR}$ V; Zahnfabrik, Bad Säckingen, Germany) against a white background. Color measurements of each sample were repeated three times by an operator, and the average of the three values were recorded. Total color changes $(\Delta E)$ were calculated using the equation (1)

$$
\Delta E=\left[(L 0-L 1)^{2}+(a 0-a 1)^{2}+(b 0-b 1)^{2}\right]^{1 / 2}
$$

where $L 0, L 1, a 0, a 1, b 0$, and $b 1$ indicate that initial light value degree, degree of light value after immersion, initial red-green coordinate value, the red-green coordinate value after immersion, initial green-blue coordinate value, and the green-blue after immersion, respectively. Light value change $(\Delta L)$ and red-green and green-blue coordinate value changes ( $\Delta a$ and $\Delta b$, respectively) were calculated using the equations (2 to 4 ).

$$
\begin{aligned}
\Delta L & =\left[(L 0-L 1)^{2}\right]^{1 / 2} \\
\Delta a & =\left[(a 0-a 1)^{2}\right]^{1 / 2} \\
\Delta b & =\left[(b 0-b 1)^{2}\right]^{1 / 2}
\end{aligned}
$$

\subsection{Statistical analysis}

The Jamovi (Version 1.0.4) as accessed by https://www.jamovi.org, program was used for statistical analysis. Normality of data distribution was checked using the Shapiro-Wilk test. Due to normal distribution, an analysis of covariance (ANCOVA) was used for the color differences.

Table 1 . The properties of the experimental and commercial composite resins used in the study.

\begin{tabular}{ccccc}
\hline \multirow{2}{*}{ Composite } & Resin Matrix & \multicolumn{2}{c}{ Fillers } \\
\cline { 3 - 5 } & & Type & $\begin{array}{c}\text { Content } \\
(\text { Vol\% })\end{array}$ & $\begin{array}{c}\text { Size } \\
(\mu \mathrm{m})\end{array}$ \\
\hline FZ & Bis-GMA, TEGDMA, UDMA, and Bis-EMA & Zirconia/Silica & 60 & $0.01-3.5$ \\
Bis-GMATTEGDMA & Bis-GMA, TEGDMA & $\mathrm{BaO} / \mathrm{SiO} 2 / \mathrm{B} 2 \mathrm{O} 3$ & 60 & 0.7 \\
Bis-EFMATEGDMA & Bis-EFMA, TEGDMA & $\mathrm{BaO} / \mathrm{SiO} 2 / \mathrm{B} 2 \mathrm{O} 3$ & 60 & 0.7 \\
UDMATTEGDMA & UDMA, TEGDMA & $\mathrm{BaO} / \mathrm{SiO} 2 / \mathrm{B} 2 \mathrm{O} 3$ & 60 & 0.7 \\
\hline
\end{tabular}


Significant differences were analysed with the Tukey's post hoc test $(a=0.05)$.

\section{Results and discussion}

UDMA- and Bis-EFMA-based composite resins exhibited significantly less $\Delta E$ and $\Delta L$ compared to Bis-GMA based composite resins $(p<0.05)$. No significant difference was found among other groups in terms of composite type $(p>0.05)$ as shown in Table 2. Tea and coffee exhibited significant differences in $\Delta E, \Delta L, \Delta a$, and $\Delta b$ compared to water and cola $(p<0.05)$. Between tea and coffee, the only difference was found concerning $\Delta a(p<0.001)$. In terms of solution type, no significant difference was found among other groups $(p>0.05)$ (Table 3$)$. The one month time period exhibited significant differences in $\Delta E, \Delta L$, $\Delta a$, and $\Delta b$ compared to one week and one day $(p<$ $0.05)$. In terms of time periods, no significant difference was found among other groups $(p>0.05)$ as shown in Table 4. Descriptive statistics of composite and solution types and time period groups regarding $\Delta E, \Delta L, \Delta a, \Delta b$ values are presented in Table 5.

Dental resin matrix is one of the important parameters that can change many physical properties of RBCs. The monomer properties, such as viscosity, chemical structure of the polymer network, crosslink density, and molecular weight can affect the mechanical properties of the RBCs [31]. The presence of water in the resin, which causes oxidation of unreacted double bonds, paves the way for the pigments to penetrate the resin [32]. In this respect, there are differences among resins in terms of discoloration of composite materials. BisEFMA is a powerful alternative to traditional monomers in terms of improved mechanical property and lower cytotoxicity [30]. However, to our knowledge there are no reports addressing the color stability of Bis-EFMA monomer-based composite resin; therefore, in this study, the first evaluation of color stability of this candidate monomer was performed.

The three-dimensional (3D) color measurement formulas CIEL*a*b* and CIE2000 are recommended by the International Organization for Standardization (ISO) for calculating color differences. Statistically related results were obtained with two formulas in a previous study [33]. In the current study, CIEL*a*b* was preferred. Additionally, due to the challenge of providing an overall picture using $\Delta E$ values alone, all of the parameters $(\Delta L, \Delta a, \Delta b)$ were presented in the study with this preference. In a previous study, clinical perceptions and acceptable threshold values were reported as $\Delta E=1$ and $\Delta E=3.7$, respectively [34]. Based on these threshold values, during almost all time periods, $\Delta E$ was higher than the threshold of perceptibility $(\Delta E=1)$ and acceptability $(\Delta E=3.7)$ regardless of the composite or solution types except FZ (up to 1 week $\Delta E=2.88-3.50$ ) and UDMAbased composites, which were immersed in water solutions (up to one month $\Delta E=2.79-3.15$ ). These outcomes indicate that discoloration is a clinical problem in all RBCs, whether the composite is experimental or commercial.

The first null hypothesis was rejected, experimental RBCs prepared with the Bis-EFMA exhibited less discoloration compared to Bis-GMA based ones. Water absorption may soften the resin matrix and increase discoloration [35], and the color stability of the RBCs has been shown to correlate with water absorption and solubility [36,37]. UDMA- and Bis-EFMA-based materials contain carbamate linkages (-NHCOO-), which cause less water absorption, while Bis-GMA-based materials contain highly polar hydroxyl groups that cause high water sorption $[30,38,39]$. In line with the findings of the present study, Bis-GMA based composite resins, which have higher water absorption, have been shown to be more susceptible to staining than UDMA- and Bis-EFMA-based composite resins (in terms of $\Delta E$ and $\Delta L$ ) [36]. Besides, it has been shown that there a correlation between the degree of conversion and both internal discoloration and water absorption exists, and as the degree of conversion increases, discoloration decreases $[36,40]$. The urethane groups in both monomers can increase the polymerization rate and provide advantages in terms of the degree of conversion compared to Bis-GMA [41]. Bis-GMA has hydrogen bonds between the hydroxyl groups, which cause disadvantages, such as very high viscosity. This structure manifests a low degree of conversion [41]. Already, in terms of both the degree of conversion and water absorption, UDMA and Bis-EFMA were shown to be superior to BisGMA [30,36].

TEGDMA was added to experimental composites to dilute monomers with higher viscosities. In this respect, it would not be a correct approach to evaluate the findings of Bis-GMA-, Bis-EFMA-, and UDMA-based experimental composites independently from TEGDMA. TEGDMA proportions may vary in composite contents, so we adjusted the TEGDMA proportion in experimental 
composites to be $50 \%$ by weight of the resin content as J. He and H. M. Kopperud [30] did. TEGDMA, which has a low molecular weight $(286 \mathrm{~g} / \mathrm{mol})$, led to an improvement in viscosity, reactivity, and final degree of conversion of the matrix phase. However, this monomer increases water sorption [42]. It has been shown in many studies that TEGDMA exhibits greater discoloration $[43,44]$. Bis-EMA has a higher molecular weight $(540 \mathrm{~g} / \mathrm{mol})$, and it reduces viscosity and allows a high degree of conversion [36]. Bis-EMA, which has less hydrophilic structure, is superior to other monomers in terms of color stability $[38,45]$. FZ, which is a commercial composite, contains Bis-GMA, TEGDMA, UDMA, and Bis-EMA monomer composition in combination [46]. In this context, it is reasonable to expect FZ to be successful in terms of color stability. However, in this study, the FZ commercial product did not exhibit superior performance to the experimental composites in terms of color stability. Consistent with the study of J. He and H. M. Kopperud [30] in which it was determined that the water absorption of Bis-EFMA-based composites and FZ is close, in the current study, Bis-EFMA provided similar color stability values as FZ. Nevertheless, the differences between the experimental composites used in the study and the FZ is attributed to the type and size distribution of

Table 2. ANCOVA Post Hoc Comparisons - Composite type (Regardless of solution type and time periods).

\begin{tabular}{|c|c|c|c|c|c|c|c|}
\hline \multirow{2}{*}{ Composite type } & \multirow{2}{*}{ Composite type } & \multicolumn{3}{|c|}{ Comparison $(\Delta E)$} & \multicolumn{3}{|c|}{ Comparison $(\Delta L)$} \\
\hline & & $\mathrm{MD}$ & SE & $\mathrm{p}_{\text {tukey }}$ & $\mathrm{MD}$ & SE & $\mathrm{p}_{\text {tukey }}$ \\
\hline Bis-GMA & UDMA & 3.374 & 0.934 & $0.002^{*}$ & 2.985 & 0.726 & $<.001^{\star}$ \\
\hline - & Bis-EFMA & 2.47 & 0.934 & $0.044^{*}$ & 2.895 & 0.726 & $<.001^{*}$ \\
\hline - & $F Z$ & 1.075 & 0.934 & 0.658 & 1.53 & 0.726 & 0.154 \\
\hline UDMA & Bis-EFMA & -0.904 & 0.934 & 0.768 & -0.09 & 0.726 & 0.999 \\
\hline - & $\mathrm{FZ}$ & -2.299 & 0.934 & 0.069 & -1.455 & 0.726 & 0.19 \\
\hline Bis-EFMA & $\mathrm{FZ}$ & -1.395 & 0.934 & 0.443 & -1.365 & 0.726 & 0.24 \\
\hline \multirow{2}{*}{ Composite type } & \multirow{2}{*}{ Composite type } & \multicolumn{3}{|c|}{ Comparison $(\Delta a)$} & \multicolumn{3}{|c|}{ Comparison $(\Delta b)$} \\
\hline & & MD & SE & $\mathrm{p}_{\text {tukey }}$ & MD & SE & $\mathrm{p}_{\text {tukey }}$ \\
\hline Bis-GMA & UDMA & 0.61833 & 0.296 & 0.161 & 1.445 & 0.727 & 0.196 \\
\hline - & Bis-EFMA & -0.13667 & 0.296 & 0.967 & 0.753 & 0.727 & 0.728 \\
\hline - & $\mathrm{FZ}$ & -0.13 & 0.296 & 0.972 & -0.35 & 0.727 & 0.963 \\
\hline UDMA & Bis-EFMA & -0.755 & 0.296 & 0.056 & -0.692 & 0.727 & 0.777 \\
\hline - & $\mathrm{FZ}$ & -0.74833 & 0.296 & 0.059 & -1.795 & 0.727 & 0.068 \\
\hline Bis-EFMA & $\mathrm{FZ}$ & 0.00667 & 0.296 & 1 & -1.103 & 0.727 & 0.429 \\
\hline
\end{tabular}

${ }^{*}$ indicates the significance $(p<0.05)$, MD: Mean Differences.

Table 3. ANCOVA Post Hoc Comparisons - Solution type (Regardless of composite type and time periods).

\begin{tabular}{|c|c|c|c|c|c|c|c|}
\hline \multirow{2}{*}{ Solution type } & \multirow{2}{*}{ Solution type } & \multicolumn{3}{|c|}{ Comparison $(\Delta E)$} & \multicolumn{3}{|c|}{ Comparison $(\Delta L)$} \\
\hline & & MD & SE & $\mathrm{p}_{\text {tukey }}$ & $\mathrm{MD}$ & SE & $\mathrm{p}_{\text {tukey }}$ \\
\hline Water & Cola & -0.506 & 0.934 & 0.949 & 0.693 & 0.726 & 0.775 \\
\hline- & Tea & -7.399 & 0.934 & $<.001^{*}$ & -5.138 & 0.726 & $<.001^{*}$ \\
\hline- & Coffee & -7.649 & 0.934 & $<.001^{*}$ & -4.985 & 0.726 & $<.001^{*}$ \\
\hline Cola & Tea & -6.892 & 0.934 & $<.001^{*}$ & -5.832 & 0.726 & $<.001^{*}$ \\
\hline - & Coffee & -7.142 & 0.934 & $<.001^{*}$ & -5.678 & 0.726 & $<.001^{*}$ \\
\hline Tea & Coffee & -0.25 & 0.934 & 0.993 & 0.153 & 0.726 & 0.997 \\
\hline \multirow{2}{*}{ Solution type } & \multirow{2}{*}{ Solution type } & \multicolumn{3}{|c|}{ Comparison $(\Delta a)$} & \multicolumn{3}{|c|}{ Comparison $(\Delta b)$} \\
\hline & & $\mathrm{MD}$ & SE & $\mathrm{p}_{\text {tukey }}$ & $\mathrm{MD}$ & SE & $\mathrm{p}_{\text {tukey }}$ \\
\hline Water & Cola & -0.377 & 0.296 & 0.582 & -1.36 & 0.727 & 0.242 \\
\hline- & Tea & -3.182 & 0.296 & $<.001^{*}$ & -3.86 & 0.727 & $<.001^{*}$ \\
\hline- & Coffee & -1.997 & 0.296 & $<.001^{*}$ & -5.07 & 0.727 & $<.001^{*}$ \\
\hline Cola & Tea & -2.805 & 0.296 & $<.001^{*}$ & -2.49 & 0.727 & $0.004^{*}$ \\
\hline- & Coffee & -1.62 & 0.296 & $<.001^{*}$ & -3.7 & 0.727 & $<.001^{*}$ \\
\hline Tea & Coffee & 1.185 & 0.296 & $<.001^{*}$ & -1.21 & 0.727 & 0.347 \\
\hline
\end{tabular}

${ }^{*}$ indicates the significance $(p<0.05)$, MD: Mean Differences.

Table 4. ANCOVA Post Hoc Comparisons - Time Periods (Regardless of composite and solution types).

\begin{tabular}{|c|c|c|c|c|c|c|c|}
\hline \multirow{2}{*}{$\begin{array}{l}\text { Time } \\
\text { Periods }\end{array}$} & \multirow{2}{*}{$\begin{array}{c}\text { Time } \\
\text { Periods }\end{array}$} & \multicolumn{3}{|c|}{ Comparison $(\Delta E)$} & \multicolumn{3}{|c|}{ Comparison $(\Delta L)$} \\
\hline & & MD & SE & $\mathrm{p}_{\text {tukey }}$ & MD & SE & $\mathrm{p}_{\text {tukey }}$ \\
\hline 1 day & 1 week & -1.57 & 0.809 & 0.130 & -1.26 & 0.628 & 0.115 \\
\hline- & 1 month & -4.58 & 0.809 & $<.001^{*}$ & -3.80 & 0.628 & $<.001^{*}$ \\
\hline 1 week & 1 month & -3.01 & 0.809 & $<.001^{*}$ & -2.54 & 0.628 & $<.001^{*}$ \\
\hline Time & Time & \multicolumn{3}{|c|}{ Comparison $(\Delta a)$} & \multicolumn{3}{|c|}{ Comparison $(\Delta b)$} \\
\hline Periods & Periods & MD & SE & $\mathrm{p}_{\text {tukey }}$ & MD & SE & $\mathrm{p}_{\text {tukey }}$ \\
\hline 1 day & 1 week & -0.0375 & 0.257 & 0.988 & -0.767 & 0.629 & 0.443 \\
\hline - & 1 month & -0.8600 & 0.257 & $0.003^{*}$ & -2.352 & 0.629 & $<.001^{*}$ \\
\hline 1 week & 1 month & -0.8225 & 0.257 & $0.004^{*}$ & -1.585 & 0.629 & $0.034^{*}$ \\
\hline
\end{tabular}

${ }^{*}$ indicates the significance $(p<0.05)$, MD: Mean Differences. 
filler, and monomer composition.

Second null hypothesis was rejected, solution type exhibited significantly different discoloration. Many investigations reported that tea and coffee were the beverages that caused the most staining, a finding in agreement with those from current investigation [47-50]. The staining mechanisms of tea and coffee, which have yellow pigments, differ from each other. The discoloration produced by tea occurs via adsorption of high polar pigments to the surface. However, the situation is different for coffee because it changes the surface color by adsorption and absorption of lower polar pigments with smaller particle sizes [51]. In this study, the

Table 5. Descriptive statistics of composite type, solution, time period groups in regard to $\Delta E, \Delta L, \Delta a, \Delta b$ values.

\begin{tabular}{|c|c|c|c|c|c|c|}
\hline Composite type & Solution & Time Period & $\Delta E($ mean $\pm S D)$ & $\Delta L($ mean \pm SD $)$ & $\Delta a($ mean \pm SD $)$ & $\Delta b($ mean $\pm \mathrm{SD})$ \\
\hline \multirow{12}{*}{$\begin{array}{l}\text { Bis-GMA } \\
\text { TEGDMA }\end{array}$} & \multirow{3}{*}{ Water } & 1 day & $4.94 \pm 1.27$ & $3.66 \pm 1.04$ & $0.060 \pm 0.0548$ & $3.28 \pm 0.909$ \\
\hline & & 1 week & $5.56 \pm 3.18$ & $4.84 \pm 3.34$ & $0.660 \pm 0.472$ & $1.96 \pm 1.62$ \\
\hline & & 1 month & $6.60 \pm 4.02$ & $6.46 \pm 4.04$ & $0.660 \pm 0.472$ & $0.880 \pm 0.712$ \\
\hline & \multirow{3}{*}{ Cola } & 1 day & $3.76 \pm 1.10$ & $2.06 \pm 1.39$ & $1.96 \pm 0.288$ & $2.20 \pm 0.866$ \\
\hline & & 1 week & $4.31 \pm 2.80$ & $3.44 \pm 3.16$ & $1.28 \pm 0.753$ & $1.46 \pm 0.961$ \\
\hline & & 1 month & $8.27 \pm 4.94$ & $7.08 \pm 4.04$ & $1.54 \pm 1.75$ & $3.40 \pm 3.21$ \\
\hline & \multirow{3}{*}{ Tea } & 1 day & $7.00 \pm 1.17$ & $4.82 \pm 1.44$ & $4.22 \pm 0.782$ & $2.52 \pm 0.853$ \\
\hline & & 1 week & $10.0 \pm 9.21$ & $5.14 \pm 8.91$ & $2.46 \pm 0.888$ & $4.94 \pm 7.69$ \\
\hline & & 1 month & $25.6 \pm 3.39$ & $19.1 \pm 3.11$ & $5.46 \pm 1.31$ & $16.1 \pm 2.27$ \\
\hline & \multirow{3}{*}{ Coffee } & 1 day & $10.3 \pm 4.46$ & $8.62 \pm 4.50$ & $3.68 \pm 0.785$ & $3.16 \pm 3.23$ \\
\hline & & 1 week & $10.6 \pm 2.84$ & $8.46 \pm 2.97$ & $2.34 \pm 1.26$ & $4.86 \pm 3.47$ \\
\hline & & 1 month & $22.6 \pm 10.7$ & $15.5 \pm 7.32$ & $3.62 \pm 1.44$ & $15.8 \pm 8.37$ \\
\hline \multirow{12}{*}{ UDMA TEGDMA } & \multirow{3}{*}{ Water } & 1 day & $2.81 \pm 1.73$ & $1.06 \pm 0.740$ & $0.560 \pm 0.329$ & $2.42 \pm 1.77$ \\
\hline & & 1 week & $2.79 \pm 2.16$ & $1.68 \pm 2.18$ & $0.240 \pm 0.261$ & $1.72 \pm 1.52$ \\
\hline & & 1 month & $3.15 \pm 1.30$ & $2.26 \pm 1.44$ & $0.480 \pm 0.335$ & $1.90 \pm 0.854$ \\
\hline & \multirow{3}{*}{ Cola } & 1 day & $6.42 \pm 5.68$ & $1.94 \pm 0.723$ & $1.22 \pm 0.829$ & $5.54 \pm 6.14$ \\
\hline & & 1 week & $5.27 \pm 2.52$ & $2.36 \pm 1.32$ & $0.840 \pm 1.01$ & $4.00 \pm 3.23$ \\
\hline & & 1 month & $4.51 \pm 3.67$ & $1.72 \pm 0.722$ & $1.26 \pm 1.19$ & $3.54 \pm 3.96$ \\
\hline & \multirow{3}{*}{ Tea } & 1 day & $7.31 \pm 1.82$ & $5.56 \pm 1.51$ & $3.14 \pm 1.23$ & $2.90 \pm 2.19$ \\
\hline & & 1 week & $11.5 \pm 2.97$ & $9.96 \pm 1.90$ & $3.36 \pm 1.30$ & $4.36 \pm 2.64$ \\
\hline & & 1 month & $11.4 \pm 3.18$ & $9.82 \pm 2.24$ & $3.98 \pm 1.66$ & $3.62 \pm 2.64$ \\
\hline & \multirow{3}{*}{ Coffee } & 1 day & $6.36 \pm 2.42$ & $5.32 \pm 2.21$ & $1.76 \pm 0.434$ & $2.64 \pm 1.84$ \\
\hline & & 1 week & $8.31 \pm 4.83$ & $5.88 \pm 2.24$ & $1.74 \pm 0.627$ & $4.54 \pm 5.61$ \\
\hline & & 1 month & $9.36 \pm 2.13$ & $5.76 \pm 3.28$ & $1.94 \pm 1.23$ & $6.06 \pm 3.11$ \\
\hline \multirow{12}{*}{$\begin{array}{c}\text { Bis-EFMA } \\
\text { TEGDMA }\end{array}$} & \multirow{3}{*}{ Water } & 1 day & $5.00 \pm 1.65$ & $2.22 \pm 1.74$ & $1.18 \pm 0.554$ & $4.10 \pm 1.30$ \\
\hline & & 1 week & $5.22 \pm 2.16$ & $4.50 \pm 2.50$ & $0.580 \pm 0.396$ & $2.12 \pm 0.983$ \\
\hline & & 1 month & $5.96 \pm 1.69$ & $5.48 \pm 1.77$ & $1.02 \pm 0.164$ & $1.74 \pm 1.23$ \\
\hline & \multirow{3}{*}{ Cola } & 1 day & $3.35 \pm 0.785$ & $1.62 \pm 1.16$ & $0.900 \pm 0.731$ & $2.48 \pm 0.864$ \\
\hline & & 1 week & $9.01 \pm 4.08$ & $4.66 \pm 3.76$ & $1.88 \pm 1.58$ & $7.06 \pm 2.75$ \\
\hline & & 1 month & $4.26 \pm 4.25$ & $1.56 \pm 1.13$ & $1.44 \pm 0.783$ & $3.50 \pm 4.23$ \\
\hline & \multirow{3}{*}{ Tea } & 1 day & $5.46 \pm 2.23$ & $1.92 \pm 1.54$ & $3.04 \pm 1.45$ & $3.78 \pm 1.91$ \\
\hline & & 1 week & $6.70 \pm 1.13$ & $2.22 \pm 1.31$ & $4.70 \pm 0.992$ & $3.60 \pm 2.17$ \\
\hline & & 1 month & $18.5 \pm 2.38$ & $14.6 \pm 2.10$ & $8.48 \pm 0.963$ & $7.18 \pm 2.98$ \\
\hline & \multirow{3}{*}{ Coffee } & 1 day & $6.75 \pm 4.04$ & $3.12 \pm 1.54$ & $1.02 \pm 0.792$ & $4.86 \pm 5.23$ \\
\hline & & 1 week & $9.46 \pm 3.39$ & $5.28 \pm 2.74$ & $1.76 \pm 0.623$ & $6.62 \pm 4.68$ \\
\hline & & 1 month & $10.3 \pm 5.50$ & $7.20 \pm 6.99$ & $3.58 \pm 0.653$ & $4.50 \pm 2.70$ \\
\hline \multirow{12}{*}{$\mathrm{FZ}$} & \multirow{3}{*}{ Water } & 1 day & $2.88 \pm 1.47$ & $6.78 \pm 10.9$ & $1.34 \pm 1.35$ & $1.14 \pm 0.893$ \\
\hline & & 1 week & $3.50 \pm 2.40$ & $6.62 \pm 11.6$ & $1.30 \pm 1.51$ & $1.16 \pm 0.684$ \\
\hline & & 1 month & $3.81 \pm 1.79$ & $6.10 \pm 8.07$ & $2.14 \pm 1.69$ & $1.76 \pm 1.16$ \\
\hline & \multirow{3}{*}{ Cola } & 1 day & $1.83 \pm 0.763$ & $0.980 \pm 0.853$ & $0.460 \pm 0.261$ & $1.34 \pm 0.493$ \\
\hline & & 1 week & $4.08 \pm 3.04$ & $2.42 \pm 2.15$ & $0.840 \pm 0.321$ & $3.12 \pm 2.23$ \\
\hline & & 1 month & $3.25 \pm 1.71$ & $0.460 \pm 0.586$ & $1.12 \pm 0.550$ & $2.90 \pm 1.76$ \\
\hline & \multirow{3}{*}{ Tea } & 1 day & $11.0 \pm 11.0$ & $9.30 \pm 9.79$ & $3.64 \pm 3.26$ & $4.10 \pm 4.42$ \\
\hline & & 1 week & $12.5 \pm 13.3$ & $8.96 \pm 11.7$ & $4.08 \pm 3.63$ & $6.84 \pm 6.69$ \\
\hline & & 1 month & $13.9 \pm 5.93$ & $8.88 \pm 3.52$ & $1.84 \pm 0.902$ & $10.5 \pm 4.95$ \\
\hline & \multirow{3}{*}{ Coffee } & 1 day & $13.9 \pm 12.2$ & $8.16 \pm 5.84$ & $2.88 \pm 2.42$ & $10.3 \pm 11.1$ \\
\hline & & 1 week & $15.3 \pm 13.7$ & $10.0 \pm 7.52$ & $3.60 \pm 3.58$ & $10.7 \pm 11.3$ \\
\hline & & 1 month & $20.8 \pm 5.36$ & $15.1 \pm 6.15$ & $6.26 \pm 6.56$ & $11.0 \pm 0.52$ \\
\hline
\end{tabular}

SD: Standard deviation 
lack of association between coffee and tea in terms of staining was consistent with findings from some previous studies [49]; however, some studies found that tea caused much more discoloration than coffee $[47,52]$. In this study, no difference was found between water and cola in terms of discoloration, a result that is consistent with the previous studies [49, 53].

Although cola, which has a low $\mathrm{pH}$, can affect the surface integrity of the material, it caused less lack discoloration than tea and coffee possibly due to the lack of yellow pigments, such as tannins [51]. Consistent with this study, many previous studies conducted on water and cola found that these solutions showed the lowest mean $\Delta E$ values [ 45 , 53-55]. Since water does not contain colorants, these color changes may be attributed to water absorption by the organic matrix.

The third null hypothesis was rejected, time periods exhibited significantly different discoloration. As the time period increased, $\Delta E$ values also increased. The analysis of immersion time alone revealed that the most noticeable discoloration occurred after 30 days. Irrespective of the type of solution used, findings revealed by previous studies, which showed that the longer staining periods increase discoloration, are consistent with the present study [45,56-59].

\section{Conclusion}

Bis-EFMA and UDMA monomers were found to be superior to Bis-GMA-based composites in terms of color stability. Besides, no significant difference was found between Bis-EFMA-based composite resins and FZ, which is used as a reference to evaluate whether a Bis-EFMA-based composite had the potential to be used as a commercial composite. Based on these findings, it was concluded that BisEFMA has the potential to be used in commercial dental composites as a substitute for Bis-GMA in terms of better color stability.

\section{Acknowledgement}

The authors would like to extend their appreciation to the Sutcu Imam University for funding the work (Project NO: 2019/1-24 M). Besides, they would like to thank Inci Dental Company who assists in the supply of experimental materials.

\section{References}

1. R. Z. Alshali, N. A. Salim, R. Sung, J. D. Satterthwaite, and N. Silikas, Dent. Mater, 31
(2015) 711.

2. N. Garg and A. Garg, "Textbook of operative dentistry", Boydell \& Brewer Ltd, New Delhi, 2010, p.300.

3. A. H. García, M. A. M. Lozano, J. C. Vila, A. B. Escribano, and P. F. Galve, Med. Oral. Patol. Oral. Cir. Bucal., 11 (2006) 215.

4. R. Lagocka, K. Jakubowska, D. Chlubek, and J. Buczkowska-Radlinska, Adv. Med. Sci., 60 (2015) 191.

5. N. Olea, R. Pulgar, P. Pérez, F. Olea-Serrano, A. Rivas, A. Novillo-Fertrell, V. Pedraza, A. M. Soto, and C. Sonnenschein, Environ. Health. Perspect., 104 (1996) 298.

6. R. Pulgar, M. F. Olea-Serrano, A. NovilloFertrell, A. Rivas, P. Pazos, V. Pedraza, J. Navajas, and N. Olea, Environ. Health. Perspect., 108 (2000) 21.

7. R. Steinmetz, N. G. Brown, D. L. Allen, R. M. Bigsby, and N. Ben-Jonathan, Endocrinology, 138 (1997) 1780.

8. E. R. Hugo, T. D. Brandebourg, J. G. Woo, J. Loftus, J. W. Alexander, and N. Ben-Jonathan, Environ. Health. Perspect., 116 (2008) 1642.

9. P. Alonso-Magdalena, I. Quesada, and A. Nadal, Nat. Rev. Endocrinol., 7 (2011) 346.

10. B. Yu, D. Liu, F. Liu, and J. He, Adv. Polym. Technol., 33 (2014) 1.

11. M. Yin, F. Liu, and J. He, J. Mech. Behav. Biomed. Mater, 57 (2016) 157.

12. S. Shi and J. Nie, Dent. Mater., 24 (2008) 530.

13. T. K. Vaidyanathan and J. Vaidyanathan, Acta. Biomater. Odontol. Scand., 1 (2015) 59.

14.B. Yu, F. Liu, and J. He, J. Mech. Behav. Biomed. Mater, 35 (2014) 1.

15. B. Yu, F. Liu, J. He, Y. He, and Z. Lin, $A d v$. Polym. Technol., 34 (2015) 1.

16. X. Liang, F. Liu, and J. He, Dent. Mater, 30 (2014) 917.

17. M. Yin, S. Guo, F. Liu, and J. He, J. Mech. Behav. Biomed. Mater, 51 (2015) 337.

18. S. Luo, W. Zhu, F. Liu, and J. He, Int. J. Mol. Sci., 17 (2016) 1.

19. X. Liu, Z. Wang, C. Zhao, W. Bu, Y. Zhang, and H. Na, J. Mech. Behav. Biomed. Mater, 77 (2018) 446.

20. J. Eick, E. Kostoryz, S. Rozzi, D. Jacobs, J. Oxman, C. Chappelow, A. Glaros, and D. Yourtee, Dent. Mater., 18 (2002) 413.

21. J. D. Eick, R. E. Smith, C. S. Pinzino, and E. L. Kostoryz, J. Dent., 34 (2006) 405.

22. C. C. Chappelow, C. S. Pinzino, S. S. Chen, L. Jeang, and J. D. Eick, J. Appl. Polym. Sci., 103 (2007) 336.

23. N. B. Cramer, C. L. Couch, K. M. Schreck, J. E. 
Boulden, R. Wydra, J. W. Stansbury, and C. N. Bowman, Dent. Mater., 26 (2010) 799.

24. M. Podgórski, E. Becka, M. Claudino, A. Flores, P. K. Shah, J. W. Stansbury, and C. N. Bowman, Dent. Mater., 31 (2015) 1255.

25. M. Podgórski, E. Becka, M. Claudino, A. Flores, P. K. Shah, J. W. Stansbury, and C. N. Bowman, Dent Mater, 31 (2015) 1263.

26. X. Wang, G. Huyang, S. V. Palagummi, X. Liu, D. Skrtic, C. Beauchamp, R. Bowen, and J. Sun, Dent. Mater., 34 (2018) 228.

27. S. Huang, M. Podgorski, X. Zhang, J. Sinha, M. Claudino, J. W. Stansbury, and C. N. Bowman, J. Dent. Res., 97 (2018) 530.

28. S. Tauscher, Y. Catel, P. Fässler, U. Fischer, and N. Moszner, J. Appl. Polym. Sci., 134 (2017) 1.

29. Y. Catel, P. Fässler, U. Fischer, C. Gorsche, R. Liska, S. Schörpf, S. Tauscher, and N. Moszner, Eur. Polym. J., 98 (2018) 439.

30. J. He and H. M. Kopperud, Dent. Mater, 34 (2018) 1003.

31. N. Moszner and U. Salz, Prog. Polym. Sci., 26 (2001) 535.

32. A. S. Sham, F. C. Chu, J. Chai, and T. W. Chow, J. Prosthet. Dent., 91 (2004) 447.

33. L. Gregor, I. Krejci, E. Di Bella, A.J. Feilzer, S. Ardu, Odontology, 104 (2016) 305.

34. G. Khashayar, P. A. Bain, S. Salari, A. Dozic, C. J. Kleverlaan, and A. J. Feilzer, J. Dent., 42 (2014) 637.

35. K. Söderholm, M. Zigan, M. Ragan, W. Fischlschweiger, and M. Bergman, J. Dent. Res., 63 (1984) 1248.

36. A. S. Fonseca, A. D. Labruna Moreira, P. P. de Albuquerque, L. R. de Menezes, C. S. Pfeifer, and L. F. Schneider, Dent. Mater., 33 (2017) 394.

37. F. M. EL-Sharkawy, N. M. Zaghloul, and A. M. Ell-kappaney, Int. J. Compos. Mater., 2 (2012) 7.

38. I. Sideridou, V. Tserki, and G. Papanastasiou, Biomaterials, 24 (2003) 655.

39. S. Venz and B. Dickens, J. Biomed. Mater. Res., 25 (1991) 1231.

40. S. Imazato, H. Tarumi, K. Kobayashi, H. Hiraguri, K. Oda, and Y. Tsuchitani, Dent. Mater. J., 14 (1995) 23.

41. I. Sideridou, V. Tserki, and G. Papanastasiou, Biomaterials, 23 (2002) 1819.
42. I. Sideridou, V. Tserki, and G. Papanastasiou, Biomaterials, 24 (2003) 655.

43. N. Gonulol and F. Yilmaz, J. Dent., 40, Suppl, 2 (2012) 64.

44. A. U. Güler, E. Güler, A. Ç. Yücel, and E. J. Ertaş, J. Appl. Oral. Sci., 17 (2009) 108.

45. N. Bahbishi, W. Mzain, B. Badeeb, H. M. Nassar, Materials (Basel), 13 (2020) 1.

46. M. Karadas, O. Hatipoglu, H. Er, and E. Akyüz Turumtay, J. Adhes. Sci. Technol., 38 (2018) 2631.

47. N. Tekce, S. Tuncer, M. Demirci, M. E. Serim, and C. Baydemir, Restor. Dent. Endod., 40 (2015) 255.

48. S. Garoushi, L. Lassila, M. Hatem, M. Shembesh, L. Baady, Z. Salim, and P. Vallittu, Acta. Odontol. Scand., 71 (2013) 144.

49. M. Karadas, Scanning, 38 (2016) 701.

50. I. Nasim, P. Neelakantan, R. Sujeer, and C. Subbarao, J. Dent., 38 (2010) 137.

51. R. Bagheri, M. Burrow, and M. Tyas, J. Dent., 33 (2005) 389.

52. M. R. Malekipour, A. Sharafi, S. Kazemi, S. Khazaei, and F. Shirani, Dent. Res. J. (Isfahan), 9 (2012) 441.

53. A. A. Al Kheraif, S. S. Qasim, R. Ramakrishnaiah, and R. Ihteshamur, Dent. Mater. J., 32 (2013) 326.

54. A. U. Guler, F. Yilmaz, T. Kulunk, E. Guler, and S. Kurt, J. Prosthet. Dent., 94 (2005) 118.

55. E. Ertas, A. U. Güler, A. C. Yücel, H. Köprülü, and E. Güler, Dent. Mater. J., 25 (2006) 371.

56. M. S. Kumar, R. Ajay, S. A. Miskeen Sahib, M. Chittrarasu, M. Navarasu, N. Ragavendran, and O. F. Burhanuddin Mohammed, J. Pharm. Bioallied. Sci., 9 (2017) 161.

57. C. Barutcigil, K. Barutcigil, M. M. Ozarslan, A. Dundar, and B. Yilmaz, J. Esthet. Restor. Dent., 30 (2018) 3.

58. A. K. Hasan, S. Sunarintyas, and D. Irnawati, Dent. J. (Majalah Kedokteran Gigi), 42 (2009) 123.

59. S. Savas, O. Colgecen, B. Yasa, and E. Kucukyilmaz, Niger. J. Clin. Pract., 22 (2019) 824. 